\title{
Conversatorio clínico patológico en el Hospital Nacional Arzobispo Loayza_2011-01.
}

\author{
Clinical Case at the Hospital Nacional Arzobispo Loayza_2011-1. \\ Editor Responsable $\quad$ : $\quad$ Dr. Enrique Cipriani Thorne ${ }^{1}$ \\ Discusión Clínica $\quad$ : $\quad$ Dr. Augusto $\mathrm{Nago}^{2}$ \\ Discusión Patológica $\quad$ : $\quad$ Dr. Roger Verona ${ }^{3}$ \\ Residente responsable : $\quad$ Dr. Edmundo Alegria ${ }^{4}$
}

\section{Enfermedad actual}

Mujer de 74 años, casada, ama de casa, natural de Lambayeque y procedente de San Juan de Miraflores. Acudió al hospital con un tiempo de enfermedad de aproximadamente tres meses, de inicio insidioso y curso progresivo, caracterizada por dolor epigástrico de leve intensidad, episódica e hiporexia. Un mes antes de acudir al hospital el dolor aumentó en frecuencia e intensidad y se agregó nauseas. Una semana antes, se agregó ictericia y prurito generalizado, y desde 4 días antes notó coluria y acolia.

Funciones Biológicas: Apetito disminuido; sed y sueño conservados; orina colúrica; deposiciones 1 vez/día y peso disminuido $10 \mathrm{~kg}$ en los últimos 3 meses.

\section{Antecedentes Personales}

Ooferectomia e histerectomía 5 años antes.

G: 2 P: 2002, FUR: a los 50 años.

No tenía antecedentes familiares importantes.

\begin{abstract}
Examen Físico
PA: 120/70, FC: 76x', FR: 18x', T: $36,6^{\circ} \mathrm{C}$

Estaba despierta, tranquila, en buen estado. Piel: ictérica, múltiples equimosis en muslo y región glútea derecha. No había edema. Cuello: no se palpaba bocio. Pulmones y cardiovascular normales. Abdomen: plano, RHA presentes, había dolor a la palpación en epigastrio y no se encontró visceromegalia. Genitales normales. Neurológico: estaba lúcida, no presentaba alteraciones de la función motora ni sensitiva y no había signos meníngeos.
\end{abstract}

\section{Exámenes auxiliares \\ Los exámenes hematológicos y bioquímicos se muestran en la tabla 1 ; su grupo sanguíneo era $\mathrm{O} \mathrm{Rh}+$. El examen de orina mostró leucocitos 2-4/c bilirrubina 3+. En la ecografía abdominal se encontró: vías biliares intrahepáticas dilatadas, colédoco $12 \mathrm{~mm}$, vesícula distendida con varios cálculos en su interior.}

1 Profesor del Departamento de Medicina. Facultad de Medicina Alberto Hurtado. Universidad Peruana Cayetano Heredia. Lima, Perú

2 Médico asistente del Departamento de Anatomía Patológica del Hospital Nacional Arzobispo Loayza. Lima, Perú

3 Profesor. Facultad de Medicina Alberto Hurtado Universidad Peruana Cayetano Heredia. Lima, Perú.

4 Médico Residente de Post-Grado en Medicina. Facultad de Medicina Alberto Hurtado Universidad Peruana Cayetano Heredia. Lima, Perú. 
Tabla 1. Exámenes de laboratorio.

\begin{tabular}{|c|c|c|}
\hline FECHA & $\mathrm{Al}$ ingreso & $\begin{array}{l}\text { A los diez } \\
\text { días }\end{array}$ \\
\hline Hematocrito (\%) / Hemoglobina (gr/dL) & $35,4 / 11,4$ & $29,5 / 9,9$ \\
\hline Leucocitos $/ \mathrm{mm}^{3}$ & 5180 & 6000 \\
\hline Abastonados (\%) & 2 & 3 \\
\hline Segmentados (\%) & 62 & 58 \\
\hline Eosinófilos (\%) & 2 & 4 \\
\hline Basófilos (\%) & 0 & 0 \\
\hline Monocitos (\%) & 4 & 4 \\
\hline Linfocitos (\%) & 30 & 31 \\
\hline Plaquetas $\mathrm{x} \mathrm{mm}^{3}$ & 303000 & 214000 \\
\hline TP (seg) & 20,6 & 13,1 \\
\hline TTP (seg) & 39,7 & \\
\hline INR & 1,67 & 1,0 \\
\hline VIH & & No reactivo \\
\hline \multirow[t]{2}{*}{ VDRL } & & No reactivo \\
\hline & 36 & \\
\hline Creatinina (mg/dL) & 0,79 & \\
\hline Proteínas totales (gr/dL) & 5,45 & \\
\hline Albumina (gr/dL) & 3,12 & \\
\hline Globulina (gr/dL) & 2,33 & \\
\hline Bilirrubinas Totales (mg/dL) & 18 & \\
\hline Bilirrubina directa (mg/dL) & 16.6 & \\
\hline Bilirrubina indirecta (mg/dL) & 1.4 & \\
\hline TGP (UI/L) & 102 & \\
\hline TGO (UI/L) & 104 & \\
\hline Fosfatasa Alcalina (UI/L) & 512 & \\
\hline Gamma Glutamil Transpeptidasa (UI/L) & 99 & \\
\hline Amilasa & 36 & \\
\hline
\end{tabular}

Grupo sanguíneo: O. Factor Rh: +

La TAC abdominal mostró dilatación de vías biliares intrahepáticas y extra hepáticas incluyendo colédoco (Figura 1); dilatación del conducto de Wirsung, asociados a duodeno engrosado e irregular.

\section{Discusión Clínica:}

\section{Dr. Augusto Nago}

Debo resaltar algunos datos importantes. La paciente tiene una enfermedad de 3 meses, de inicio insidioso y curso progresivo; inicia con epigastralgia de leve intensidad, que un mes después aumenta su intensidad, se acompaña de nauseas y en la semana previa al ingreso nota ictericia y prurito generalizado, y cuatro días antes hay equimosis en extremidades inferiores. Refiere además coluria e hipocolia, y durante el periodo de su enfermedad había perdido 10 kilos de peso.

En el examen físico los datos importantes son: la ictericia, las equimosis en la región glútea derecha, sin antecedente de aplicación de inyectables o traumatismo y el dolor a la palpación en epigastrio. 
La paciente tenía hemoglobina en 11,4 gr/dL que en alrededor de 10 días disminuyó a 9,9 gr/dL; bilirrubinas totales en $18 \mathrm{mg} / \mathrm{dL}$ a predominio directo, transaminasas sobre $100 \mathrm{UI} / \mathrm{L}$, fosfatasa alcalina incrementado 4 veces el valor máximo. Proteínas totales de 5,45 y albúmina de 3,12 gr/dL, el tiempo de protrombina inicialmente prolongada y asumo que después de la administración de vitamina $\mathrm{K}$ mejoró retornando a niveles normales. En orina es importante el hallazgo bilirrubina $3+$.

Igualmente, y solo para recordar los datos encontrados en los estudios de imágenes, la ecografía mostró vías biliares intrahepáticas dilatadas, colédoco dilatado y vesícula distendida conteniendo varios cálculos. En la tomografía abdominal, se remarca la dilatación de las vías biliares y del conducto pancreático describiendo además irregularidad y engrosamiento a nivel de duodeno.

Se puede resaltar la presencia de tres síndromes: 1) un síndrome general, caracterizado por hiporexia y baja de peso; 2) epigastralgia, dolor a la palpación de epigastrio y náuseas en algún momento de su enfermedad; y 3) el síndrome ictérico, caracterizado por ictericia, coluria, acolia, hiperbilirrubinemia a predominio directo, elevación de las transaminasas y fosfatasa alcalina 4 ó 5 veces el rango normal.

Salta a la vista el problema de ictericia de tipo obstructivo posiblemente extrahepático que es donde centraremos la discusión. Dentro de las causas más o

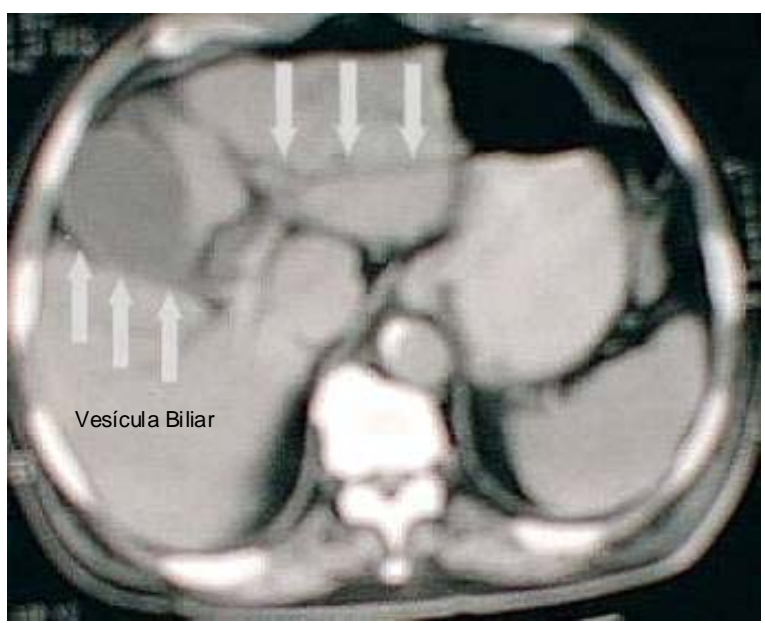

Figura 1. TAC de abdomen. Dilatación de las vías biliares principales y de la vesícula biliar Imagen modificada (1). menos frecuentes de ictericia tenemos: cálculos en el colédoco, carcinoma en la región ampular, hepatitis viral aguda e ictericia colestásica por drogas (2).

No había antecedente de cólicos que suele ocurrir en los casos de cálculos en colédoco u otros que apoyen los cuadros de hepatitis viral aguda e ictericia colestásica por drogas.

Por la historia corta de la ictericia no nos permite decir cuál fue la evolución. Generalmente en el cuadro de cálculos en el colédoco, el dolor es un cólico tipo biliar que no es el caso de la paciente, porque el dolor que presentó era epigástrico y no podemos ver la evolución por el corto tiempo de su enfermedad.

La pérdida de peso se enmarca dentro del cuadro de carcinoma periampular o ampular. El tamaño del hígado puede variar dependiendo de la etapa de la enfermedad. En la etapa inicial, el tamaño del hígado no se afecta, pero cuando la obstrucción es de mayor tiempo puede crecer.

La presencia de área vesicular sensible y fiebre, puede haber en un cuadro agudo de tipo obstructivo sobre todo cuando hay problema de colangitis; en este caso no lo hubo según la historia: El color de las heces es importante dado que cuando hay hipocolia generalmente nos indica que hay obstrucción o dificultad en el drenaje biliar; se presenta principalmente en las lesiones obstructivas a nivel de colédoco.

Los niveles de bilirrubina sérica dependen también el tiempo transcurrido, sea el caso de impactación de cálculos en el colédoco o un cuadro obstructivo. A mayor tiempo transcurrido los niveles son cada vez mayores, por lo menos en este grupo donde la tendencia es que se vaya obstruyendo cada vez más y dificultando el drenaje biliar.

La fosfatasa alcalina plasmática aumenta en los cuadros obstructivos; la elevación de transaminasas séricas resaltan en la hepatitis viral aguda; en los estudios radiográficos tomográfico o ecográfico se puede evidenciar el cálculo sobre todo a nivel vesicular; el tercio inferior del colédoco muchas veces es difícil de visualizar, pero lo saltante es la observación de dilatación del conducto secundaria a obstrucción, pero sobre todo cuando la dilatación es de ambos conductos, tanto biliar como pancreático lo que nos orienta a pensar en una obstructivo en la parte baja donde confluyen estos dos conductos. 
Generalmente cuando estamos frente a un cuadro de ictericia de causa no bien definida por la historia clínica, las pruebas bioquímicas o por los marcadores, el primer paso es buscar en la ecografía, si hay una vía biliar dilatada. Por lo general, cuando no hay dilatación de la vía biliar, dentro del estudio muchas veces se termina en biopsia hepática para ver el daño a nivel de hígado. Pero, cuando hay dilatación de la vía biliar se recurre a otros procedimientos; por ejemplo, cuando la obstrucción es proximal, a la colangiografia transparietohepática, cuando la obstrucción es distal una colangiopancreatografía retrógrada endoscópica es la alternativa no sólo de diagnóstico, sino también terapéutico. En los casos de cálculos, se determina el tamaño y se puede extraer a través de la papilotomía; en el caso de una masa operable resecable se hace la cirugía, pero cuando es no operable, el drenaje correspondiente.

En el caso de colestasis sin dilatación de los conductos biliares intra o extrahepáticos, a veces hay hepatitis viral de tipo colangiolitico pero el cuadro clínico y los marcadores orientan el diagnóstico. En este grupo, dentro del diagnóstico diferencial está la cirrosis biliar primaria, que es una entidad que ocurre en el sexo femenino y que suele empezar con prurito; dos datos son muy importantes: anticuerpos mitocondriales positivo y fosfatasa alcalina persistentemente elevada y en un rango muy alto. Estos son los casos que muchas veces terminan en biopsia hepática.

Para coledocolitiasis, el antecedente de colecistectomía y de cólico de tipo biliar, y los estudios como la colangiografía o la colangiografía retrógrada endoscópica son importantes para el diagnóstico. La colangitis esclerosante generalmente compromete las vías biliares intrahepáticas, aunque algunas veces también al colédoco; muchas veces se asocia a procesos de tipo autoinmune como la colitis ulcerativa crónica inespecífica.

La historia de la paciente menciona dilatación del conducto biliar y del conducto pancreático, por lo tanto tenemos que asumir que el problema de compresión o de obstrucción está en la parte baja en la zona donde desembocan estos dos conductos. Como diagnóstico diferencial, coledocolitiasis es buena posibilidad, más aún por la presencia de cálculos a nivel vesicular.

Pero podemos estar frente a un Tumor de Klatskin (tumor maligno de la confluencia biliar), a un síndrome de Mirizzi (compresión biliar extrínseca), a un tumor de colédoco, a un tumor cabeza de páncreas cuyo crecimiento puede comprimir la vía biliar, a un ampuloma que puede crecer hacia el exterior del duodeno o hacia el conducto de Wirsung, ocasionando en ambos casos problemas de tipo obstructivo, o en casos poco frecuentes como parásitos que pueden obstruir el colédoco como áscaris o fasciola hepática o la presencia de dilatación de ambos conductos por cualquier lesión ubicada en la segunda porción del duodeno que altere el drenaje de la secreción biliopancréatica.

En los casos de litiasis de colédoco, un cálculo se puede impactar en la porción terminal, dificultando el drenaje de la bilis y también del conducto pancreático; estos casos muchas veces se acompañan de pancreatitis aguda.

En el Tumor de Klatskin, una tumoración a nivel de la confluencia biliar compromete la salida de la bilis, trayendo como consecuencia la dilatación de los conductos intrahepáticos, como se ve en este caso.

El síndrome de Mirizzi, consiste en un cálculo en el cuello de la vesícula que causa obstrucción del colédoco por compresión extrínseca, se puede presentar con o sin fístula colecistocoledociana. Todos sabemos que la litiasis vesicular produce un cuadro de colecistitis aguda, se enclava en el cístico, pero no produce ictericia porque el drenaje biliar es normal.

Los tumores de páncreas que comprimen la cabeza del páncreas, pueden comprimir la zona de drenaje de conducto biliar y del conducto pancreático, originando dilatación de ambos conductos. Entonces, tanto el tumor propio del páncreas como el de la papila de la ampolla de Vater, van a producir dilatación ambos conductos.

Aparte de la ictericia obstructiva que mencionamos que la lesión debería estar en la parte distal de la vía biliar y del conducto pancreático para originar dilatación de ambos conductos, hay dos datos muy importantes: Primero, el estudio de imágenes muestra que el duodeno se encuentra engrosado e irregular, y segundo, la baja de peso. Supongo que para llegar al diagnóstico se debió estudiar la segunda porción del duodeno, por doble motivo, por el dolor epigástrico y las náuseas y por la anemia.

Sabiendo que el cáncer más frecuente en el tubo digestivo es en el estómago, amerita realizar una endoscopia digestiva alta para descartar en primer lugar un cáncer gástrico por la gran baja de peso, por la edad de la paciente, pero por la ictericia con dilatación de 
ambos conductos biliar y pancreático tenemos que ver si hay alguna alteración en la papila de Vater o en las zonas vecinas como causa de una obstrucción.

Para avanzar un poco más hemos revisado las causas de lesiones en la segunda porción duodenal y dentro de ello señalamos las posibilidades más frecuentes, de menos a más. Sin embargo, tuberculosis una patología frecuente en Perú y por las formas tan variadas como se presenta en el lado digestivo, podría producir una lesión en la segunda porción del duodeno que pueda alterar el drenaje de la bilis, puede ser una posibilidad. Otra posibilidad aunque rara es la strongiloidiasis que puede afectar duodeno y yeyuno. Hemos visto casos de strongiloidiasis en la segunda porción duodenal que hacen cuadros suboclusivos; basado en estos casos, podemos extrapolar que si el compromiso está en la papila de Váter podrá dar obstrucción.

Por la edad de la paciente, el deterioro de su estado general, la baja de peso y la anemización, tenemos que plantear la posibilidad de una tumoración en la segunda porción duodenal. Para ir de menos a más en frecuencia, los sarcomas son los menos frecuentes dentro del tubo digestivo. La patología tumoral poco frecuente a nivel de intestino delgado, dentro de las cuatro variedades de tumores que se suelen presentar, la menos frecuente es el sarcoma que se presenta a edad más temprana y puede comprometer el estado general; pero, no creo que sea lo tenga la paciente.

El tumor carcinoide ocurre con mayor frecuencia a nivel del apéndice y su comportamiento casi siempre es benigno, siendo los malignos los que se localizan en el intestino delgado (3); se presenta a edad más temprana y cuando hacen metástasis pulmonar o hepático producen el clásico síndrome carcinoide

Las otras dos variedades son: linfoma y adenocarcinoma. Los linfomas en el intestino tienden a localizarse con más frecuencia en la porción distal del intestino delgado a nivel de íleon incluso en íleon terminal, mientras que el adenocarcinoma se localiza con más frecuencia a nivel del duodeno, luego en yeyuno y menos en íleon.

Algunos sarcomas como el leiomiosarcoma se localizan frecuentemente en la parte media y distal. Los tumores de papila crecen hacia adentro, pero hay situaciones donde estas tumoraciones se extienden y van infiltrando la parte netamente duodenal, pero también ocurre al revés, tumores de la segunda porción duodenal periampular que se extienden e ir comprometiendo el drenaje.

Los tumores de intestino delgado tienen un crecimiento similar al de los tumores de colon, sobre todo del lado izquierdo donde se observa un crecimiento en forma anular; de tal manera que viendo la imagen se puede apreciar la zona comprometida. Este es el signo del "corazón de la manzana" o "la manzana mordida" como algunos lo denominan, a diferencia de un problema inflamatoria donde hay adelgazamiento sin irregularidad; esto es útil desde el punto de vista radiológico o endoscópico.

Bueno, luego de la revisión del caso podemos plantear como posibilidad diagnóstica una tumoración en una porción duodenal que altere el drenaje biliopancreático, puede ser un adenocarcinoma duodenal, sea un ampuloma que infiltra al duodeno o un tumor duodenal que infiltra la ampolla, ambas situaciones pueden estar originar obstrucción en el drenaje de la vía biliar y del conducto pancreático. Creo que en este caso el diagnóstico está dado por el resultado de una endoscopia digestiva alta y la biopsia correspondiente.

\section{Dr. Cipriani:}

Quiero hacer un par de comentarios. En este caso la amilasa sérica fue normal; si fuera una lesión benigna o un tumor maligno resecable esto influye bastante en el pronóstico en relación con la cirugía. Cuando hay pancreatitis aguda o pancreatitis crónica, agregada a la lesión primaria, el acto operatorio es complicado y el postoperatorio es mucho más complicado cuando hay una pancreatitis aguda.

Como punto dos, no hay que olvidarse que muchas veces el carcinoma de páncreas se inicia con una pancreatitis aguda con amilasas altas y eso lo he visto varias veces y está muy bien descrito, entonces cuando ustedes vean una elevación de las amilasas sin ictericia, sospechen que puede ser una neoplasia primaria de páncreas y si ven ictericia con amilasa elevada lo más probable es que sea una coledocolitiasis y si hay pancreatitis aguda el manejo de la coledocolitiasis desde el punto de vista quirúrgico es bastante más complicado y la morbilidad es mayor.

\section{Dr. Alegría:}

Antes de pasar a la discusión patológica a cargo del Dr. Verona, hay que comentar que esta paciente fue vista por el servicio de gastroenterología quienes al observar los hallazgos descritos en la tomografía realizaron una endoscopía digestiva alta. En la 
endoscopía observaron a nivel del bulbo duorenal la ampolla de Vater “abombada” (aprox. $4 \mathrm{~cm}$ ), aumentada de volumen, de superficie irregular, de borde eritematoso y de aspecto infiltrativo y friable al roce; se realizaron biopsias. Como posibilidades diagnósticas se planteó, una lesión infiltrativa probable ampuloma maligno de la ampolla de Vater y gastritis erosiva antral.

\section{Discusión Anatomo-Patológica}

\section{Dr. Roger Verona}

Se recibieron varios fragmentos de tejido blando friable con sangre que en algunos casos, correspondía a la mucosa duodenal, se observaron glándulas cortadas en diferentes direcciones causando espacios en blanco que corresponden a la luz, glándulas y células caliciformes (Figura 2).

Entre los espacios glandulares hay mucha diferencia entre sus tamaños y el epitelio también está muy alterado (Figura 3); vamos a ver en detalle con mayor aumento. Entre las estructuras tubulares, el estroma casi no existe y prácticamente sólo se aprecia epitelio glandular; hay proliferación del componente epitelial glandular en desmedro del componente estromal. Hay que destacar también, la diferencia entre el tamaño y forma de las células y de los núcleos.

En otros focos hay estructuras que corresponden a papilas como si se estuvieran desprendiendo de la matriz primaria (Figura 4), aquí no hay tejido normal. Hay epitelio hacia adentro y hacia fuera, hay una estructura vacía al parecer por problema del corte, pero se observan células todas de diferente tamaño y forma, y de los núcleos; esto es lo que se conoce como

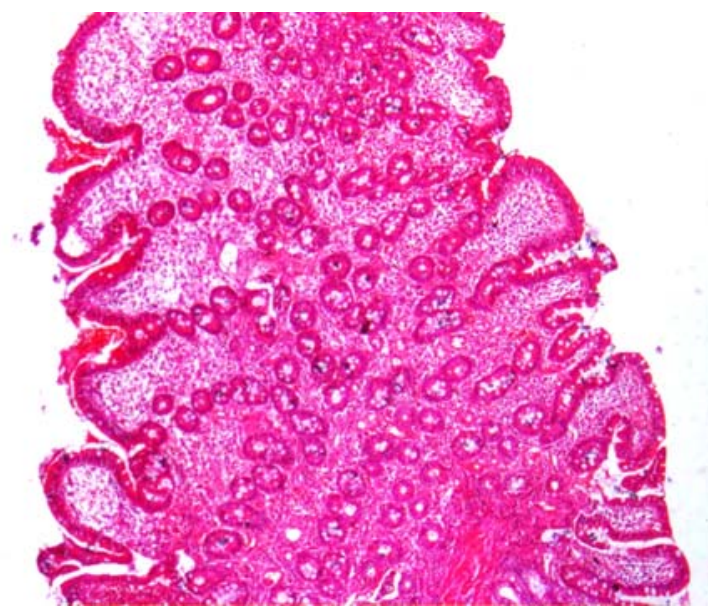

Figura 2. Microfotografía a mediano aumento con tinción $\mathrm{H}$-E. Se aprecian glándulas cortadas en diferentes direcciones causando espacios en blanco que corresponden a la luz intestinal, así como células caliciformes.

anisonucleosis, anisocitosis o atipia nuclear y atipia celular.

Son varios los focos en que hay básicamente lesión tumoral, pero también se reconocen algunas estructuras tubulares. Cuando hay dificultad porque las lesiones neoplásicas son poco diferenciadas, hay que buscar estos focos para observar si el epitelio es el que se está transformando porque también podría también ser un linfoma, en donde las células que proliferan no están en el epitelio sino en el estroma y cuando son muy diferenciadas las células epiteliales se parecen a linfocitos, o los linfocitos son muy grandes y se parecen a las células epiteliales. Obviamente si se observan glándulas deja de ser linfomatoso.
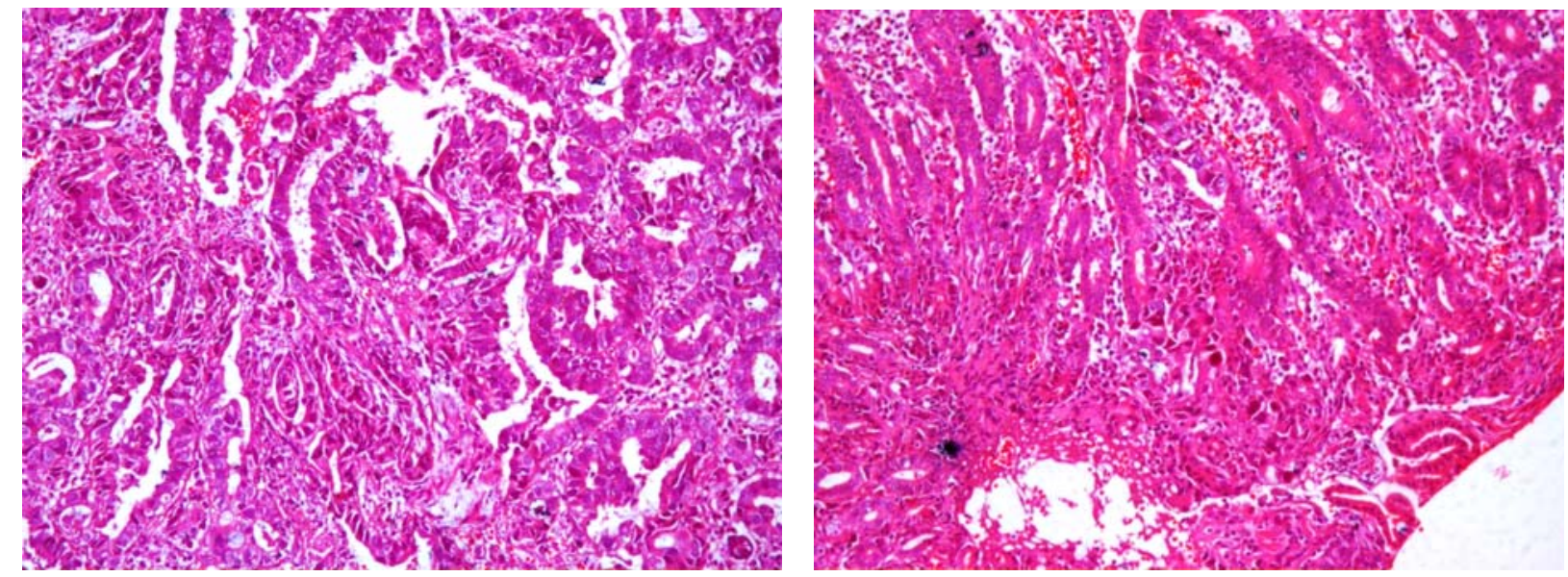

Figura 3. Microfotografía a mediano aumento con tinción H-E. Se observan espacios glandulares con mucha diferencia en sus tamaños, el epitelio también está muy alterado. 
Se puede reconocer epitelio glandular normal, con áreas de células cilíndricas con núcleos muy grandes, alargados; de diferentes tamaños y formas presencia de nucléolos prominentes, que a los patólogos sirve para calificar una lesión de neoplásica. Los núcleos en las células normales están siempre hacia la base, si los núcleos están más arriba, o más abajo, tienen diferentes formas o tamaños, y mitosis anormal, son características histológicas inequívocas de una lesión epitelial maligna.

En general, la neoplasia maligna epitelial se denomina carcinoma y si forma una glándula, adenocarcinoma. El término nos dice que viene de un epitelio glandular o que en su diferenciación tumoral forma glándulas. En el tubo digestivo, hay glándulas y tejido epitelial, pero para el patólogo es importante hacer la correlación con los hallazgos de la endoscopía. Por ejemplo, si la lesión está en la tercera porción del duodeno o está frente a la papila o han sacado la papila, entonces no puede ser ampuloma, sería es un carcinoma a secas; pero si la biopsia se tomó de la papila que se veía alterada, entonces sería ampuloma, o carcinoma o adenocarcinoma de papila o de la ampolla de Váter (3).

El término de carcinoma o adenocarcinoma ampular, hace referencia a la ubicación topográfica, y al tipo histológico de origen, es decir epitelial, que está en la ampolla y que es maligno. ¿Y por qué? Porque para que se llame ampular tiene que nacer precisamente del

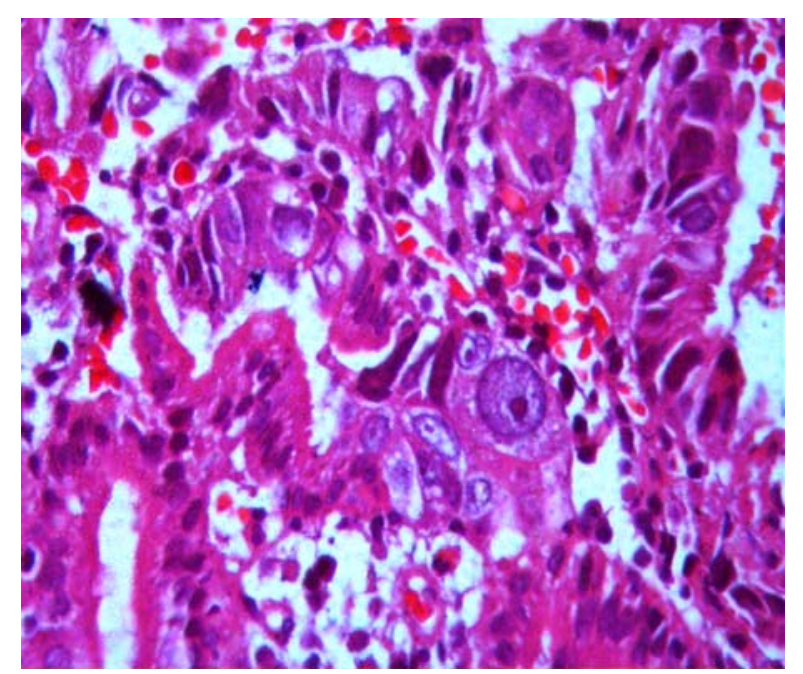

Figura 4. Microfotografía a gran aumento con tinción $\mathrm{H}$-E. Este tejido es completamente anormal hay epitelio hacia afuera y hacia adentro; todas las células tienen diferente tamaño y forma de los núcleos; hay atipia severa nuclear y celular. epitelio de la ampolla, porque puede haber tumores en otras localizaciones.

En el diagnóstico diferencias se plantean con frecuencia a los problemas inflamatorios, litiasis que ya pasó y dejó la zona con inflamación; adenocarcinoma o parásitos como Ascaris lumbricoides que migran por el colédoco.

Prácticamente todos los tumores de la ampolla de Váter son carcinomas y personalmente nunca he visto otro tipo de tumor en esa localización; esto fue señalado por el profesor Nago.

\section{Dr. Alegría:}

La paciente después de la obtención del resultado anátomo-patológico, fue evaluada por cirugía procediéndose a resección y derivación biliodigestiva. Actualmente la paciente continúa su seguimiento en oncología médica.

El reporte operatorio fue: Se realizó maniobra de Kocher y palpándose tumor dependiente de la segunda porción duodenal, se realiza hepatoyeyunostomía en Y de Roux a $30 \mathrm{~cm}$ del ángulo de Treitz con micril en un plano. Se le realizó colecistectomía. No se menciona si hubo infiltración tumoral.

\section{Dr. Verona:}

La vesícula biliar no tenía lesión neoplásica sólo colecistitis crónica. No recibimos más especímenes, por eso creemos que la lesión ha quedado ahí, no se ha resecado toda la lesión. Salvo mejor opinión de los especialistas, esta es una de las pocas neoplasias malignas del tubo digestivo que tiene buen pronóstico si se hace buena resección $(3,4)$.

\section{Dr. Nago:}

Efectivamente el ampuloma es un tumor localizado y que con una adecuada cirugía, se obtiene buenos resultados. Llama la atención que solo hayan hecho cirugía paliativa. La cirugía realizada no parece ser la operación de Whipple, que es lo que se debería haber realizado, que es de alto riesgo pero que bien hecha y sin problemas postoperatorios inmediatos tiene buen pronóstico.

\section{Dr. Cipriani:}

Quiero hacer un comentario adicional: A esta paciente indudablemente le administraron vitamina $\mathrm{K}$, puesto que el tiempo de protrombina se normalizó y eso indica que tenía un hígado con una función 
preservada. En los pacientes con hepatopatía crónica (cirrosis o hígado infiltrado por neoplasia), por más vitamina K que le administren no mejoran el tiempo de protrombina, esta es una diferenciación importante que hay que hacer.

En pacientes con ictericia severa y no sepamos el diagnóstico, este procedimiento ayuda mucho al diagnóstico de la lesión hepática. La administración de la vitamina $\mathrm{K}$ siempre es parenteral, no se puede dar por vía oral porque no se absorbe, recordar que la vitamina K es liposoluble, y requiere bilis en el intestino.

\section{REFERENCIAS BIBLIOGRÁFICAS}

1. Jordán A, Cruz D, Bello R, Alejo O, Alonso N, Alfonso O. Adenocarcinoma de la ampolla de Vater. A propósito de un caso. Rev Med Electrón 2010; 32(5). URL disponible en: http://scielo.sld.cu/scielo.php?pid=S16 84-18242010000500011\&script=sci_arttext. (Fecha de acceso: 22 de marzo del 2011).

2. Pratt D, Kaplan M. Jaundice. En: Kasper D, Braunwald E, Fauci A, Hauser S, Longo D, Jameson JL.Harrison’s Principles of Internal Medicine, 16th edition. New York: McGraw-Hill Medical Publishing Division ; 2005. p. 238243.

3. Kulke M, Mayer R. Carcinoid Tumors. N Engl J Med 1999; 340:858-868.

4. Carter JT, Grenert JP, Rubenstein L, Stewart L, Way LW. Tumors of the ampulla of Vater. Histopathologic classification and predictors of survival. J Am Coll Surg 2008; 207(2):210-8. 